\title{
Analisis Sidik Jari Kromatografi Lapis Tipis Rimpang Temu Mangga (Curcuma mangga)
}

Penulis

Afiliasi

\author{
Makmum Syafi'i ${ }^{1}$, Eti Rohaeti ${ }^{1}$, Wulan Tri Wahyuni ${ }^{1,2}{ }^{2}$, Mohamad Rafi ${ }^{1,2}$, Dewi Anggraini \\ Septaningsih ${ }^{2}$
}

${ }^{1}$ Departemen Kimia, Fakultas Matematikan dan Ilmu Pengetahuan Alam, Institut Pertanian Bogor, Indonesia

${ }^{2}$ Pusat Studi Biofarmaka Tropika, Institut Pertanian Bogor, Indonesia

\section{Kata Kunci \\ ○ Curcuma mangga \\ $\supset$ kromatografi lapis tipis \\ $\rightarrow$ sidik jari}

Diterima 5 September 2018 Direvisi 2 November 2018 Disetujui 26 November 2018

*Corresponding author Wulan Tri Wahyuni Jalan Tanjung Kampus IPB, Dramaga, Babakan, Dramaga, Bogor, Jawa Barat 16680 wulantriws@gmail.com

\section{ABSTRAK}

Profil sidik jari kromatografi lapis tipis (KLT) dapat dimanfaatkan untuk kendali mutu bahan baku maupun produk tumbuhan obat. Penelitian ini bertujuan mengembangkan metode analisis sidik jari rimpang temu mangga (Curcuma mangga) untuk kendali mutunya. Rimpang kering temu mangga diekstraksi menggunakan metanol dan dianalisis sidik jari KLT. Kloroform:etil asetat (8.5:1.5) merupakan fase gerak optimum yang memisahkan 11 pita dari rimpang temu mangga dengan keterpisahan yang baik dan memiliki pita khas biru tua $\left(R_{\mathrm{f}} 0.36\right)$. Demetoksikurkumin terdeteksi pada rimpang temu mangga dengan warna jingga kecoklatan pada UV 366 $\mathrm{nm}\left(R_{\mathrm{f}} 0.48\right)$ setelah diderivatisasi dengan pereaksi asam sulfat $10 \%$. Pengujian spesifitas terhadap rimpang lain dalam satu genus, rimpang temu mangga menunjukan pola yang berbeda. Validasi metode analisis sidik jari KLT memenuhi kriteria keberterimaan, sehingga metode ini dapat digunakan untuk kendali mutu rimpang temu mangga.

\section{PENDAHULUAN}

Temu mangga (C. mangga) merupakan salah satu spesies dari genus Curcuma yang banyak digunakan di Indonesia sebagai obat tradisioal (jamu). Rimpang merupakan bagian temu mangga yang paling banyak digunakan sebagai bahan baku obat tradisional karena rimpang temu mangga memiliki khasiat sebagai obat maag, diare, penghilang nyeri saat haid, keputihan, serta mengobati jerawat dan bisul (Tedjo et al. 2005). Rimpang segar temu mangga memiliki ciri khas berwarna kuning muda dan memiliki bau khas seperti bau buah mangga, sehingga mudah dibedakan dengan rimpang lain yang berkerabat dekat dengannya. Namun demikian, serbuk kering rimpang temu mangga akan sulit dibedakan dari serbuk kering rimpang tumbuhan yang berkerabat dengannya seperti bangle, kunyit, dan temulawak. Harga jual serbuk rimpang temu mangga juga lebih mahal dibandingkan rimpang-rimpang tersebut, sehingga dapat memicu terjadinya subtitusi bahan baku obat herbal yang berbasis temu mangga. Oleh karena itu perlu dilakukan identifikasi dan kendali mutu agar khasiat, keamanan, dan 
mutu obat herbal tetap terjaga.

Identifikasi terhadap bahan baku memerlukan suatu metode analisis. Salah satu metode analisis yang sering digunakan dalam kendali mutu bahan baku ialah pendekatan sidik jari. Pendekatan sidikjari akan memvisualisasi secara keseluruhan metabolit dalam sampel (Lin et al. 2006). Teknik kromatografi merupakan alternatif yang dapat digunakan untuk menunjukkan pola sidik jari keseluruhan dengan merepresentasikan keragaman komponen yang terdapat pada tanaman obat tanpa memperhatikan jenisnya (Liang et al. 2004), khususnya kromatografi lapis tipis (KLT). Analisis sidik jari KLT dapat dilakukan secara kualitatif, yaitu menganalisis profil hasil pemisahan berdasarkan jumlah, posisi, warna, intensitas serta $R_{f}$ (retardation factor) pita yang dihasilkan. Kromatografi lapis tipis memiliki kelebihan berupa mudah dalam preparasi sampel, sederhana, biaya operasional relatif murah karena semua komponen sampel dan standar diujikan dalam waktu yang sama, volume pelarut yang digunakan sedikit, selektif dan sensitif, serta kromatogramnya dapat diamati secara visual (Kimura et al. 2008).

Analisis sidik jari dengan KLT telah dilakukan untuk identifikasi kunyit, bangle, dan temulawak (Rafi et al. 2011); pegagan (Centella asiatica)(James dan Dubery 2011); Potentilla (Swieboda et al. 2014); dan phyllanthus amarus (Ketmongkhonsit et al. 2015). Di dalam tulisan ini telah dikembangkan suatu metode analisis sidik jari rimpang temu mangga menggunakan kromatografi lapis tipis. Metode yang telah dikembangkan digunakan untuk mengidentifikasi temu mangga dari tiga jenis rimpang tumbuhan yang berkerabat dekat dengannya.

\section{METODE}

\section{Alat dan Bahan}

Alat

Peralatan yang digunakan, yaitu KLT aplikator semiotomatis Camag Linomat 5 (CAMAG, Muttenz, Swiss), bejana kromatografi twin trough (CAMAG, Muttenz, Swiss), CAMAG Reprostar 3 (CAMAG, Muttenz, Swiss), aplikasi winCATS (CAMAG, Muttenz, Swiss), dan ultrasonikator Branson 1510 (Branson, Danbury, USA).

\section{Bahan}

Bahan-bahan yang digunakan terdiri atas pelat KLT silica gel 60 F254 20×20 cm (Merck, Darmstadt, Jerman); n-heksana pa (Merck, Darmstadt, Jerman), dietil eter pa (Merck, Darmstadt, Jerman), diklorometana pa (Merck, Darmstadt, Jerman), kloroform pa (Merck, Darmstadt, Jerman), etil asetat pa (Merck, Darmstadt, Jerman), etanol pa (Merck, Darmstadt, Jerman), aseton pa (Merck, Darmstadt, Jerman), metanol pa (Merck, Darmstadt, Jerman), asetonitril pa (Merck, Darmstadt, Jerman), asam sulfat (Merck, Darmstadt, Jerman).

Rimpang temu mangga yang digunakan terdapat 5 sampel yang diambil dari beberapa lokasi. Selain itu digunakan produk jamu, serbuk rimpang temu mangga, rimpang bangle, temulawak dan kunyit (Tabel 1).

\section{Ekstraksi Simplisia}

Serbuk sampel ditimbang sebanyak $1 \mathrm{~g}$ dan ditambahkan dengan $10 \mathrm{~mL}$ metanol dan diekstraksi selama 30 menit menggunakan ultrasonikator dengan frekuensi $42 \mathrm{kHz}$ pada suhu ruang. Ekstrak disaring ke dalam botol yang bersih kemudian ditutup rapat.

Tabel 1 Asal dan Kode Sampel

\section{Asal Sampel}

Rimpang temu mangga asal Desa Cihanjawar, Kecamatan Nagrak, Kabupaten

Sukabumi, Jawa Barat

Rimpang temu mangga asal Pasar Anyar Bogor, Jawa Barat

Rimpang temu mangga asal Pasar Merdeka Bogor, Jawa Barat

Rimpang temu mangga asal Pasar Bogor Bogor, Jawa Barat

Rimpang temu mangga asal Pasar Senen, Jakarta Pusat

Produk jamu serbuk rimpang temu mangga asal Pasar Senen, Jakarta Pusat

Rimpang bangle asal kebun Biofarmaka IPB, Bogor, Jawa Barat

Rimpang temulawak asal kebun Biofarmaka IPB, Bogor, Jawa Barat

Rimpang kunyit asal kebun Biofarmaka IPB, Bogor, Jawa Barat
Kode Sampel

M1

M2

M3

M4

M5

J

B

L

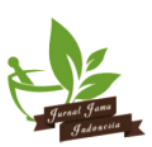




\section{Preparasi Pelat dan Kondisi Aplikasi Sampel}

Pelat KLT silika gel 60 F254 dipotong dan dikembangkan dalam bejana kromatografi yang telah dijenuhkan dengan metanol. Pelat dikeringkan menggunakan oven dengan suhu $105^{\circ} \mathrm{C}$ sampai kering. Pelat yang telah kering digunakan untuk aplikasi sampel.

Penotolan sampel menggunakan KLT aplikator semiotomatis, yaitu Camag Linomat 5. Kondisi aplikasi sampel, yaitu gas pembawa menggunakan gas nitrogen, sampel diaplikasikan konstan dengan laju 70 $\mathrm{nL} /$ detik, aplikasi volume sampel sebesar $15 \mu \mathrm{L}$, lebar pita $8 \mathrm{~mm}$, dan jarak antar spot pita sebesar $4 \mathrm{~mm}$.

\section{Pemilihan Fase Gerak}

Ekstrak M diaplikasikan pada pelat. Pelat yang telah dilakukan penotolan ekstrak dikembangkan dalam bejana yang telah dijenuhkan dengan pelarut tunggal sebanyak $10 \mathrm{~mL}$ selama 30 menit. Pelarut yang digunakan, yaitu n-heksana, dietil eter, asetonitril, aseton, diklorometana, kloroform, etil asetat, etanol, metanol, dan kombinasi beberapa pelarut. Pelat dikembangkan hingga fase gerak mencapai tinggi $8 \mathrm{~cm}$ dari posisi aplikasi ekstrak. Setelah pengembangan selesai, pelat dikeluarkan dan dikeringkan pada suhu ruang, kemudian diamati kromatogramnya.

\section{Pembuatan Pereaksi Pewarna, Deteksi, dan Derivatisasi Komponen (Reich dan Schibili 2006)}

Derivatisasi komponen dilakukan dengan cara pelat dicelupkan menggunakan pereaksi asam sulfat $10 \%$ dan dikeringkan menggunakan oven pada suhu $100{ }^{\circ} \mathrm{C}$ selama 10 menit. Pelat yang telah kering diamati pada sinar tampak dan UV $366 \mathrm{~nm}$.

\section{Validasi metode}

Kondisi dengan fase gerak terpilih selanjutnya dilakukan validasi metode. Parameter validasi metode yang dilakukan meliputi: Pertama presisi dilakukan dengan 3 kali pengulangan dan 3 hari yang berbeda (presisi antara). Kedua ketegaran (robustness) dilakukan dengan pengembangan pelat pada perbedaan tipe bejana (twin trough dan flat bottom) dan jarak pengembangan $(7 \mathrm{~cm}$ dan $8 \mathrm{~cm})$. Ketiga spesifitas dilakukan dengan perbandingan analisis sidik jari rimpang temu mangga dari beberapa lokasi (M1-5) dibandingkan dengan produk jamu serbuk rimpang temu mangga (J), rimpang bangle (B), temulawak (L) dan kunyit (K).

\section{HASIL DAN PEMBAHASAN \\ Fase Gerak Terbaik}

Pemilihan fase gerak terbaik dilakukan dengan mengembangkan pelat kromatografi lapis tipis yang telah diaplikasikan ekstrak temu mangga dengan 9 pelarut tunggal yang memiliki tingkat kepolaran berbeda. Pola sidik jari kromatografi lapis tipis yang dihasilkan dari pengembangan 9 pelarut tunggal dipilih tiga pelarut yang menghasilkan pita terbanyak dengan keterpisahan yang baik. Pelarut yang dipilih adalah kloroform, diklorometana, dan etil asetat. Ketiga pelarut tunggal tersebut dikombinasikan menjadi 2 fase gerak campuran, yaitu kloroform:diklorometana, dan kloroform:etil asetat. Kombinasi ini dilakukan dengan beberapa perbandingan. jumlah pita yang dihasilkan pada deteksi UV $254 \mathrm{~nm}$, UV $366 \mathrm{~nm}$, dan total jumlah pita keseluruhan pada berbagai komposisi fase gerak ditampilkan pada Gambar 1.

\section{Jumlah Pita}

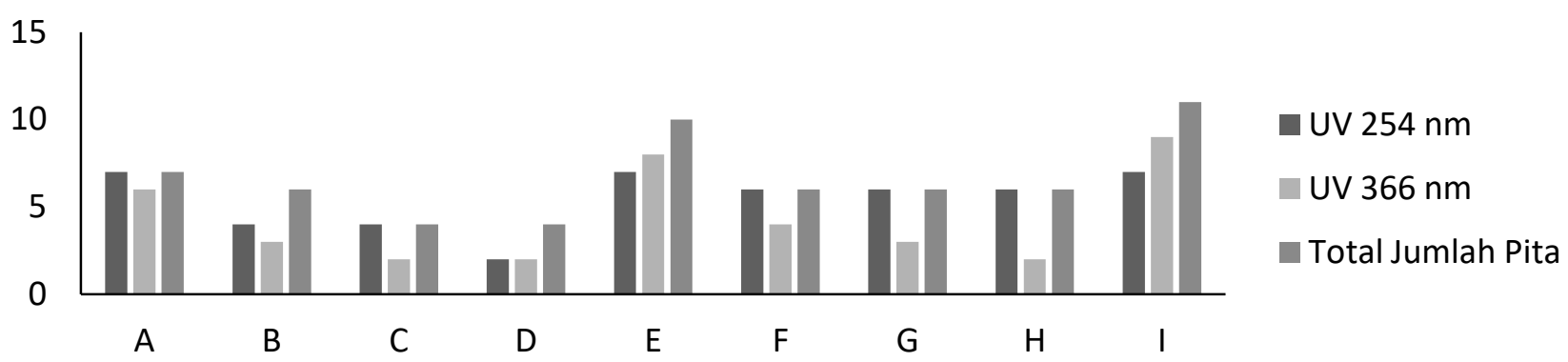

Gambar 1 Komposisi campuran fase gerak dan total jumlah pita kloroform:diklorometana dengan perbandingan (A) 9:1, (B) 7:3, (C) 5:5, (D) 2:8, dan kloroform:etil asetat dengan perbandingan (E) 9:1, (F) 7:3, (G) 5:5, (H) 1:9, (I) 8.5:1.5. 
Komposisi pelarut yang berbeda memberikan jumlah pita yang berbeda. Hal ini disebabkan perbedaan tingkat kepolaran pelarut untuk memisahkan senyawa yang terkandung dalam rimpang temu mangga. Jumlah pita terbanyak pada ekstrak temu mangga diperoleh pada komposisi fase gerak campuran kloroform dan etil asetat (9:1) yaitu 10 pita. Intensitas warna yang rendah pada beberapa pita diduga senyawa memiliki konsentrasi yang rendah. Selanjutnya, komposisi kloroform:etil asetat (9:1) dihitung nilai resolusi masing-masing pitanya untuk menentukan keterpisahan pitanya.

Keterpisahan antar pita juga merupakan faktor penting dalam kromatografi lapis tipis. Keterpisahan antar pita dikatakan baik jika memiliki nilai resolusi yang baik $(>1.5)$. Nilai resolusi eluen campuran kloroform:etil asetat (9:1) tidak memenuhi syarat keterpisahan yang baik (Tabel 2), sehingga dilakukan modifikasi kembali komposisi fase gerak campuran antara kloroform dengan etil asetat. Komposisi fase gerak campuran kloroform:etil asetat (8.5:1.5) dipilih. Komposisi fase gerak campuran kloroform:etil asetat (8.5:1.5) dipilih sebagai fase gerak terbaik yang memiliki 7 pita pada deteksi UV $254 \mathrm{~nm}, 9$ pita pada deteksi UV $366 \mathrm{~nm}$, dan 11 pita pada deteksi UV 366 $\mathrm{nm}$ setelah derivatisasi (Gambar 2). Fase gerak terbaik yang diperoleh digunakan untuk analisis selanjutnya yaitu validasi metode.

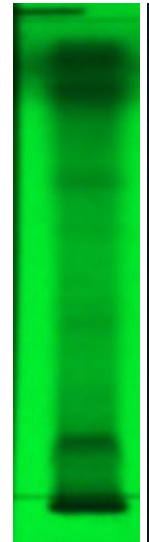

A
B

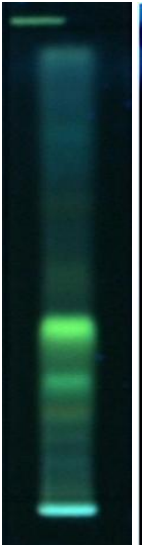

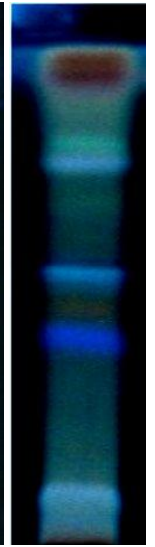

C
Gambar 2 Pola sidik jari KLT serbuk M1 komposisi fase gerak kloroform:etil asetat $(8.5: 1.5)$. Deteksi yang digunakan (A) UV $254 \mathrm{~nm}$, (B) UV 366 $\mathrm{nm}$, dan (C) UV $366 \mathrm{~nm}$ setelah derivatisasi.

\section{Presisi}

Uji presisi dilakukan pada tiga pelat yang berbeda pada hari yang sama. Jumlah, posisi, intensitas, dan warna pada pita merupakan parameter yang menentukan analisis presisi pada kromatografi lapis tipis. Pengamatan presisi antara dilakukan pada dua hari berikutnya. Berdasarkan hasil analisis yang dilakukan, tidak ada perbedaan yang signifikan dari jumlah, letak, warna, dan intensitas pita dari hasil

Tabel 2 Nilai resolusi pita fase gerak kloroform:etil asetat (9:1 dan 8.5:1.5) pada deteksi $366 \mathrm{~nm}$

\begin{tabular}{cccccc}
\hline Komposisi Perbandingan Fase Gerak & Pita & Jarak pita & Lebar pita & $\boldsymbol{R}_{\mathbf{F}}$ & Resolusi \\
\hline Kloroform : etil asetat $(8.5: 1.5)$ & 1 & 0.90 & 0.10 & 0.11 & 9.00 \\
& 2 & 1.30 & 0.10 & 0.16 & 2.67 \\
& 3 & 1.70 & 0.20 & 0.21 & 1.60 \\
& 4 & 2.25 & 0.30 & 0.28 & 1.60 \\
& 5 & 3.10 & 0.40 & 0.39 & 2.43 \\
& 6 & 4.00 & 0.30 & 0.50 & 3.60 \\
& 7 & 5.20 & 0.20 & 0.65 & 6.00 \\
Kloroform : etil asetat & 8 & 7.50 & 0.20 & 0.94 & 15.30 \\
(9: 1$)$ & 9 & 7.70 & 0.10 & 0.96 & 2.00 \\
\hline & 2 & 0.70 & 0.10 & 0.09 & 7.00 \\
& 2 & 1.00 & 0.10 & 0.13 & 3.00 \\
& 3 & 1.25 & 0.10 & 0.16 & 1.67 \\
& 4 & 1.60 & 0.20 & 0.20 & 1.00 \\
& 5 & 2.50 & 0.50 & 0.31 & 2.57 \\
& 6 & 4.00 & 0.20 & 0.50 & 7.50 \\
& 7 & 7.30 & 0.20 & 0.91 & 16.50 \\
\hline
\end{tabular}


pengembangan yang telah dilakukan (Gambar 3). Pada pola sidik jari, tiga buah pita dipilih untuk diamati perubahan migrasi yang mewakili bagian paling bawah $\left(X, R_{f} 0.10\right)$, tengah $\left(Y, R_{f} 0.36\right)$, dan atas $\left(Z, R_{f} 0.95\right)$. Pita $X, Y$, dan $Z$ dihitung pada masing-masing pelat (uji presisi) dan hari (uji presisi antara). Selisih nilai $R_{f}$ setiap pita yang didapat berkisar 0-0.02 untuk uji presisi dan berkisar 0.01-0.04 untuk uji presisi antara. Hal ini menunjukkan bahwa hasil uji presisi dan presisi antara dapat diterima, karena syarat selisih nilai $R_{\mathrm{f}}$ tidak lebih dari 0.02 untuk uji presisi dan tidak lebih dari 0.05 untuk uji presisi antara (Reich dan Schibli 2006).

\section{Spesifitas}

Spesifisitas metode pengujian rimpang temu mangga diukur dengan membandingkan sidik jari rimpang temu mangga dengan tanaman obat lain yang memiliki kesamaan secara fisik dan juga berkerabat dekat dengannya. Sampel serbuk rimpang bangle (B), kunyit (K), dan temulawak (L) dipilih sebagai pembanding karena berkerabat dekat dengan serbuk rimpang temu mangga. Serbuk $B, K$, dan $L$ tersebut cukup sulit dibedakan dengan serbuk rimpang temu mangga dan mungkin dapat dijadikan sebagai pemalsu dari serbuk rimpang temu mangga.

Hasil analisis KLT yang dilakukan terhadap serbuk temu mangga dari beberapa lokasi, B, L, dan K menunjukkan kromatogram yang cukup berbeda nyata (Gambar 4). Pola sidik jari dari keempat tanaman berbeda dari jumlah pita, dan warna pita yang dimiliki. Rimpang $\mathrm{M}, \mathrm{B}, \mathrm{L}$, dan $\mathrm{K}$ masing-masing memiliki 11,13 , 12, dan 10 pita. Rimpang temu mangga (M) memiliki satu pita berwarna biru tua yang dapat dijadikan sebagai ciri khas dan pembeda dengan rimpang lain

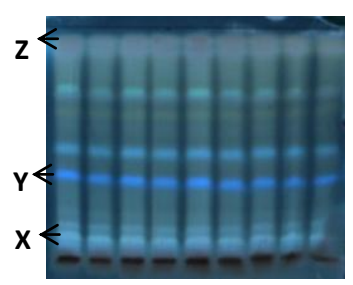

Pelat 1

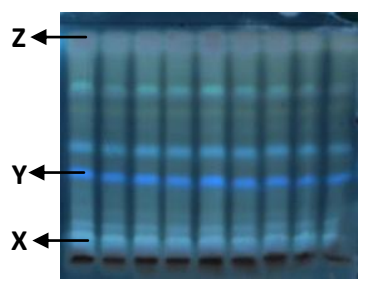

Hari 1

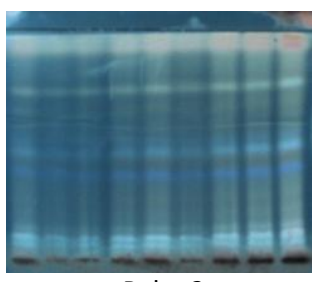

Pelat 2

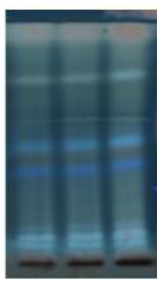

Hari 2

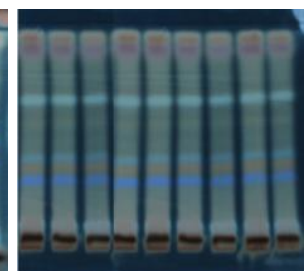

Pelat 3

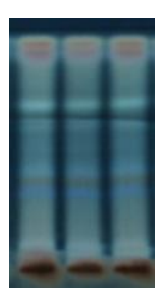

Hari 3

Gambar 3 Pola sidik jari KLT temu mangga, bangle, kunyit, dan temulawak pada uji ketegaran jarak pengembangan dengan deteksi UV $366 \mathrm{~nm}$ setelah derivatisasi.

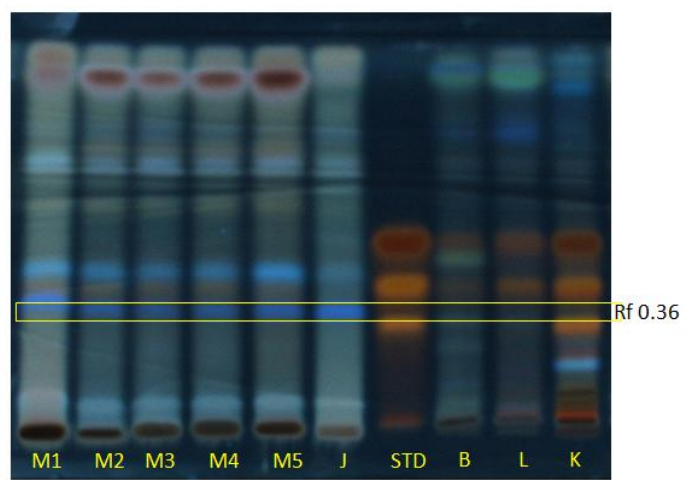

Gambar 4 Spesifitas pola sidik jari KLT serbuk rimpang temu mangga dari 5 tempat berbeda, yaitu M1, M2, M3, M4, M5; produk serbuk jamu rimpang temu mangga (J); standar kurkuminoid, (a) kurkumin, (b) demetoksikurkumin, (c) bisdemetoksikurkumin. 


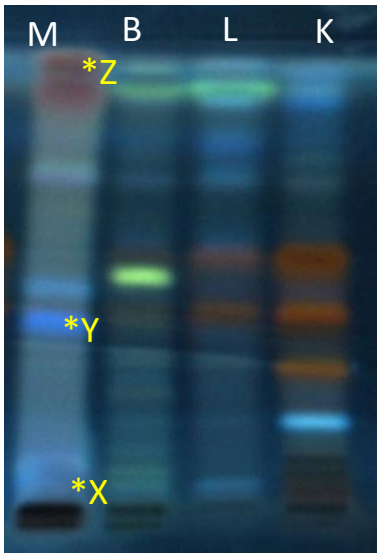

(a)
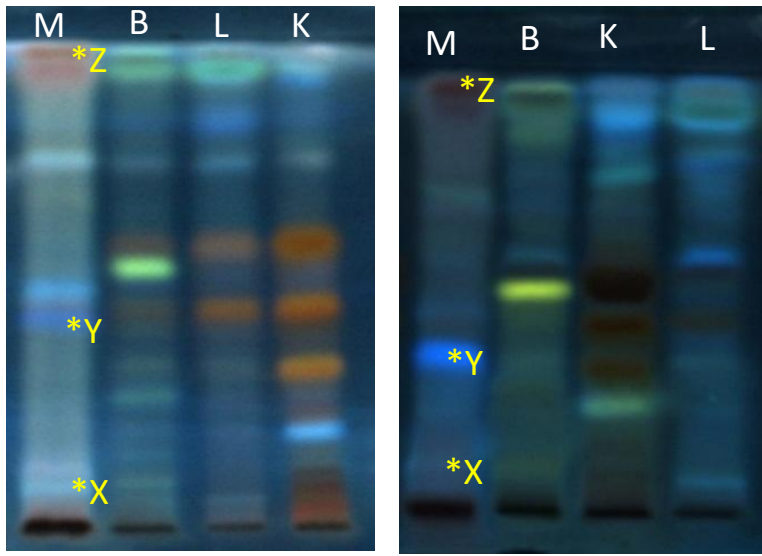

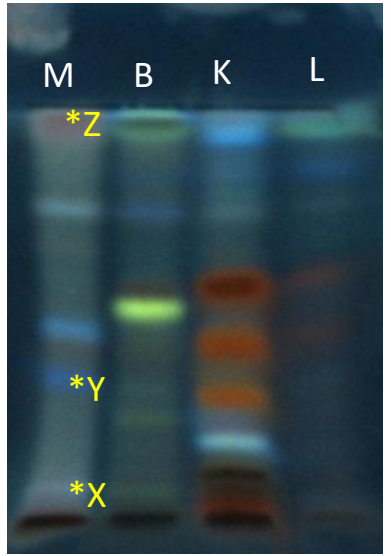

(b)

Gambar 5 Pola sidik jari KLT M1, B, L, dan K pada uji ketegaran tipe bejana (a) dan jarak pengembangan (b) dengan deteksi UV $366 \mathrm{~nm}$ setelah derivatisasi.

dengan nilai $R_{\mathrm{f}}$ sebesar 0.36 .

Salah satu kandungan kimia yang dimiliki rimpang temu mangga, yaitu demetoksikurkumin. Pola sidik jari dari 5 sampel rimpang temu mangga yang diperoleh dari berbeda-beda tempat terlihat mengandung senyawa demetoksikurkumin $\left(\begin{array}{lll}R_{\mathrm{f}} & 0.48\end{array}\right)$ yang menghasilkan warna jingga kecoklatan dengan intensitas warna yang rendah (Gambar4). Sementara itu, rimpang bangle dan temulawak mengandung senyawa kurkumin dan demetoksikurkumin; sedangkan rimpang kunyit mengandung kurkumin, demetoksikurkumin, dan bisdemetoksikurkumin. Pola sidik jari yang dihasilkan antara M1, M2, M3, M4, M5, dan J tidak terlihat berbeda dari jumlah pita yang dihasilkan. Namun, intensitas warna beberapa pita terlihat berbeda. Hal ini diduga konsentrasi suatu senyawa yang dimiliki rimpang temu mangga berbeda dari tempat yang berbeda.

\section{Ketegaran}

Parameter yang dilakukan pada uji ketegaran, yaitu ketegaran tipe bejana dan ketegaran jarak pengembangan. Ketegaran tipe bejana dilakukan untuk membandingkan hasil pengembangan pelat pada bejana twin trough dan flat bottom. Pola sidik jari yang dihasilkan menunjukkan pengembangan dengan bejana twin trough maupun flat bottom menghasilkan jumlah pita yang sama (Gambar $5 a$ ). Selisih nilai $R_{\mathrm{f}}$ dari 3 pita $X, Y$, dan $Z$ tidak lebih dari 0.05 sehingga parameter ketegaran tipe bejana memenuhi kriteria keberterimaannya. Uji ketegaran jarak pengembangan dilakukan dengan membandingkan pola sidik jari KLT temu mangga pada jarak pengembangan $8 \mathrm{~cm}$ dan 7 $\mathrm{cm}$. Pita pada jarak pengembangan $8 \mathrm{~cm}$ dan $7 \mathrm{~cm}$ menghasilkan jumlah yang sama (Gambar $5 b$ ). Pita X, Y, dan Z memiliki selisih nilai $R_{\mathrm{f}}$ maksimum tidak lebih dari 0.05 sehingga parameter ketegaran jarak pengembangan memenuhi kriteria keberterimaannya.

\section{SIMPULAN}

Metode analisis sidik jari kromatografi lapis tipis rimpang temu mangga telah berhasil dikembangkan. Fase gerak terpilih adalah kloroform:etil asetat (8.5:1.5) yang mampu memisahkan 11 pita pada serbuk rimpang temu mangga dengan deteksi menggunakan UV 366 $\mathrm{nm}$ setelah diderivatisasi menggunakan pereaksi asam sulfat $10 \%$. Oleh karena itu metode ini dapat digunakan untuk kendali mutu rimpang temu mangga.

\section{DAFTAR PUSTAKA}

James JT, Dubery IA. 2011. Identification and Quantification of Triterpenoid Centelloids in Centella asiatica (L.) Urban by Densitometric TLC. Journal of Planar Chromatography. 24(1):82-87.

Ketmongkhonsit P, Chaichantipyuth C, Palanuvej C, Thitikornpong W, Sukrong S. 2015. A validated TLCimage analysis method for detecting and quantifying bioactive phyllanthin in Phyllanthus amarus and commercial herbal drugs. 
Songklanakarin Journal Science Technology. 32037 (3): 319-326

Kimura M, Fujimura $M$, Yoshida $M$, Takeshi T, Naoko TA. 2008. An easy method to identify 8-keto-15hydroxytrichothecenes by thin layer chromatographic. Mycotoxins. 58 : 115-117.

Liang YZ, Xie P, Chan K. 2004. Quality control of herbal medicines. Journal of Chromatography B. 812: 5370.

Lin CY, Viant, MR, and Tjeerdema RS. 2006. Metabolomics: methodologies and application in the environmental sciences. Journal of Pesticides Science. 31 (3): 245-251.

Rafi M, Rohaeti E, Miftahuddin A, Darussman LK. 2011. Differentiation of Curcuma xanthorriza and Zingiber cassumunar by thin layer chromatography fingerprint analysis. Indonesian Journal of Chemistry. 11(1): 71-74

Reich E, Shibli A. 2006. High Performance Thin Layer Chromatography for The Analysis of Medicinal Plants. New York (US): Thieme Medical Publishers,

Swieboda R, Jozwiak A, Jozwiak G, Hajnus MW. 2014. Thin layer chromatography and chemometric studies of selected Potentilla species. American Journal of Analytical Chemistry. 5:1109-1120.

Tedjo A, Sajuthi D, Darusman LK. 2005. Aktivitas kemoprevensi ekstrak temu mangga. Jurnal Kesehatan. 9(2): 57-62. 